\title{
Literatura e História: reflexões acerca das possibilidades de diálogos entre as áreas
}

\author{
Literatura and History: reflections about the possibility of dialogue \\ between the areas
Literatura e historia: reflexiones sobre la posibilidad de diálogo entre las áreas

\author{
Ariane Avila Neto de Farias ${ }^{1}$ \\ Mariane Pereira Rocha ${ }^{2}$ \\ Ânderson Martins Pereira ${ }^{3}$
}

\begin{abstract}
Resumo
O século XX produz diferentes estudos que afirmam a possibilidade de aproximação entre História e Literatura. Além disso, são muitos os teóricos que entendem tais termos como áreas que se entrecruzam. Desta maneira, cada vez mais historiadores percebem as páginas literárias como meio para o entendimento dos âmbitos histórico e social de determinadas épocas, bem como são diversos os

literatos que compreendem a importância da história em sua escrita. A partir de tais apontamentos, o presente trabalho tem como principal objetivo, tomando como base os trabalhos de autores como Hayden White (2001), Roger Chartier (1994) e outros, refletir acerca da utilização da literatura como fonte de pesquisa histórica e demonstrar o constante crescimento dos debates sobre o tema aqui estudado.
\end{abstract}

Palavras-chave: Literatura; História; fonte histórica.

\begin{abstract}
The twentieth century brings different studies that affirm a possibility of approach between History and Literature. There are also many theorists who understand these terms as intertwined areas. In this way, more historians perceive literary pages as a mean for the understanding of the historical and social values of determined epochs, just as there are several literates who understand the importance of history in their writing. Taking for granted such presumptions, the present work has as the principal aim, basing itself in Hayden White (2001), Roger Chartier (1994) and others, to discuss about the use of literature as a source of historical researchand to demonstrate the steady growth of debates on the subject studied here.
\end{abstract}

Keywords: Literature; History; historical source.

\section{Resumen}

El siglo XX produce diferentes estudios que afirman la posibilidad de acercar Historia y Literatura. Además, muchos teóricos entienden estos términos como áreas que se cruzan. De esta manera, cada vez más historiadores perciben las páginas literarias como un medio para comprender las esferas históricas y sociales de ciertos períodos, así como la literatos que entienden la importancia de la historia en sus escritos. A partir de estas notas, el presente trabajo tiene como objetivo principal, basado en los trabajos de autores como Hayden White (2001), Roger Chartier (1994) y otros, reflexionar sobre el uso de la literatura como fuente de investigación histórica y demostrar el constante crecimiento de los debates sobre el tema estudiado aquí.

Palabras clave: literatura; Historia; fuente histórica

\footnotetext{
${ }^{1}$ Doutoranda em Letras/Universidade Federal do Rio Grande (FURG), arianenetof@ gmail.com

${ }^{2}$ Doutoranda em Letras/Universidade Federal de Pelotas (UFPel), marianep.rocha@gmail.com

${ }^{3}$ Doutorando em Letras/ Universidade Federal do Rio Grande do Sul (UFRGS), andersonmartinsp@ gmail.com
} 


\section{Considerações iniciais}

Os debates acerca das aproximações entre História e Literatura datam de muito tempo. O diálogo entre essas duas áreas é um campo de pesquisa que se desenvolveu significativamente no Brasil a partir dos anos 1990 e, hoje, se trata de uma temática promissora em relação às pesquisas e trabalhos publicados no meio acadêmico (PESAVENTO, 2006, p. 02). São diversos os novos objetos, abordagens e temáticas que surgem, modificando profundamente a produção intelectual dos historiadores e dos literatos. Não é de hoje que diferentes teóricos se questionam sobre os limites entre tais áreas e, por consequência, sobre as fronteiras entre realidade e ficção.

Ao se partir "do pressuposto de que a história como conhecimento é sempre uma representação do passado e que toda fonte documental para produzir esse conhecimento também o é” (BORGES, 2010, p. 94) se faz importante a reflexão acerca da aproximação entre a História e a Literatura. Nesse sentido, na atualidade, há diferentes questões que articulam o debate que aproxima as narrativas histórica e literária, ao entender ambas como discursos que respondem às indagações dos homens sobre o mundo, enxergamo-las como narrativas que respondem às perguntas, expectativas, desejos e temores sobre a realidade, que oferecem o mundo como texto. É, dessa maneira, que as ideias defendidas por Aristóteles de que a ficção e a arte estariam completamente distantes do real e de que o historiador "só poderia falar a respeito daquilo que aconteceu" e de que caberia ao poeta falar apenas "sobre o que poderia acontecer" (HUTCHEON, 1991, p.142) vão perdendo sua força e sentido. Assim, as constantes discussões sobre o tema trazem à tona a dificuldade na distinção dos dois campos.

Entende-se a História como representação do passado, instrumento de designação de acontecimentos registrados pela escrita ou oralmente. Já a Literatura, que tem sua definição repensa de acordo com o século, compreende, independente da época, textos de ficção de todo tipo, bem como o estudo e a análise dos fenômenos que envolvam tais textos. Para Antonie Campagnon,

A literatura, ou o estudo literário, está sempre imprensada entre duas abordagens irredutíveis: uma abordagem histórica, no sentido amplo (o texto como documento), e uma abordagem linguística (o texto como fato da língua, a literatura como arte da linguagem). (COMPAGNON, 1999, p. 30) 
Percebe-se a partir dessas definições que esses termos carregam questionamentos bastante complexos em seu escopo. No confronto deles, distinguem-se dois aspectos que tornam a determinação de sua atuação uma zona cinzenta: o primeiro decorrente da constatação de que os textos literários são/podem ser fatos históricos e, portanto, conforme Compagnon, exigem uma abordagem histórica, e o segundo, a partir da reflexão de que o discurso perpassa ambas áreas, história e literatura e, através dele, as fronteiras entre as áreas podem ser dissolvidas.

No que concerne ao espaço reservado a História, de acordo com Sandra Pesavento, esse seria regido pelo vínculo que vai estabelecer com seu objeto, sendo seu objetivo o de chegar a uma verdade sobre o acontecido que mais se aproxima com o passado, sua maior diferença em relação à Literatura (2004, p. 82). Sobre o mesmo tema, a teórica Valdeci Borges (2010) coloca a História "[c]omo processo social e como disciplina, e a literatura, como uma forma de expressão artística da sociedade possuidora de historicidade e como fonte documental para a produção do conhecimento histórico" (BORGES, 2010, p. 94).

Pelo exposto acima, o presente trabalho objetiva, a partir dos apontamentos de influentes teóricos da atualidade, refletir acerca das aproximações, que ganharam força com a chegada do século XX, entre História e Literatura, sugerindo o papel importante da segunda na construção da primeira. Compreende-se aqui, a interdisciplinaridade como oportunidade para o enriquecimento no ensino da disciplina História e no desenvolvimento da historiografia, considerando-se que toda produção cultural apresenta sua historicidade, que é construída em um tempo e espaço.

Nesse sentido, buscando a reflexão acima proposta, este artigo delineia-se pela leitura de teóricos que discorrem acerca do tema aqui estudado. Para tanto, a leitura de estudiosos como Hayden White (2001), Beatriz Sarlo (2007), Linda Hutcheon (1991), Roger Chartier (1994) e Sandra Pesavento (2003) são relevantes para a construção de um estudo que ratifique as possíveis aproximações entre História e Literatura, demonstrando o quão híbridas são tais áreas.

O historiador Hayden White, um dos principais estudiosos da temática, afirma que “antes da Revolução Francesa, a historiografia, entendida como a escrita da história, era considerada, convencionalmente, uma arte literária. [...] Era tida como um ramo da retórica, com sua natureza 'fictícia' geralmente reconhecida" (2001, p.39). Isto é, era por meio de técnicas ficcionais, do exercício literário, que se dava a representação de fatos. White frisa ainda que o passado nos mostra que em algum momento: 


\begin{abstract}
A história passou a ser contraposta à ficção, e sobretudo ao romance, como representação do "possível" ou apenas do "imaginável". E assim nasceu o sonho de um discurso histórico que consistisse tão somente nas afirmações factualmente exatas sobre um domínio de eventos. (2001, p.139)
\end{abstract}

O teórico também salienta que -indo ao encontro do difundido por Aristóteles, no período do início do século XIX -cabia ao historiador o papel de suprimir qualquer traço ficcional do discurso. A História deveria trilhar um caminho oposto ao da Literatura. A primeira estaria preocupada com a escrita do real/factual. Entretanto, salienta White, que mesmo naquela época, não estava bem claro o fato de que em um discurso, na medida em que este é elaborado por um sujeito, os fatos não falam por si. Segundo o mesmo, com objetivo de organizar os elementos que compõe um fato, era exercício do historiador a utilização das mesmas estratégias usadas por um poeta, encaminhando a escrita da História para um caminho de vinculação a escrita da Literatura.

Sobre tais aproximações, Sandra Pesavento em História \& História Cultural, afirma que:

[...] a História é uma espécie de ficção, ela é uma ficção controlada, e, sobretudo pelas fontes, que atrelam a criação do historiador aos traços deixados pelo passado. [...] A História se faz como resposta a perguntas e questões formuladas pelos homens em todos os tempos. Ela é sempre uma explicação sobre o mundo, reescrita ao longo das gerações que elaboram novas indagações e elaboram novos projetos para o presente e para o futuro, pelo que reinventam continuamente o passado (2003, p. 58-59).

Desta forma, a escrita da História é, então, entendida como um construto intertextual; sendo a leitura, instrumento de interpretação dos historiadores, empregada, em uma ótica relacional entre o documento utilizado na pesquisa, à historiografia e à teoria congruente ao tema escolhido. A utilização de tal método possui papel fundamental no processo de pesquisa, além de possibilitar que demais pesquisadores, assim como os leitores, possam trilhar o mesmo trajeto na perspectiva de convergir com a narrativa histórica apresentada ou refutá-la.

Tais reflexões corroboram com o entendimento de que tanto História quanto Literatura são formas de explicar o nosso presente, assim como de inventar o passado e pensar o futuro, utilizando-se de estratégias retóricas que transformam em narrativa os fatos sobre os quais aborda. Ambas são formas de representar questões que são pertinentes aos homens da época em que são produzidas, possuindo um público destinatário e leitor. Os dois tipos de narração também pressupõem estratégias de sistematização do real, procurando coerência nos laços e nexos que dependem dos dados e significações que são levados a seu público (PESAVENTO, 2006, p. 03). 
É importante destacar ainda que mesmo dentro da literatura há questionamentos sobre o lugar da ficção. Compagnon lembra que nas livrarias britânicas, "encontra-se, de um lado, a estante Literatura e, de outro, a estante Ficção; de um lado, livros para a escola e, de outro, livros para o lazer, como se a Literatura fosse a ficção entediante, e a Ficção, a literatura divertida" (COMPAGNON, 1999, p. 30). Assim, percebe-se que existe, dentro da esfera do literário, determina expectativa de compromisso com o real.

Já para Lukács (1966), os cidadãos europeus começam a perceber o papel da história em virtude das revoluções civis. Para o autor, esses movimentos sociais perpassam o literário e o motivam a englobar essas inquietações. No mesmo movimento, um novo gênero desperta na pós-modernidade, necessita nova definição e se legitima por Hutcheon (1991). A autora demonstra que a pós-modernidade se apropria do passado, mas o questiona sob o julgamento de seu próprio contexto. Contudo, teorias e criações de textos que deem conta da especificidade sociais demonstram a necessidade do homem de narrar sua história. Hutcheon (1991) pontua que o espaço da literatura de narração histórica não apenas se legitima, mas tanto ela como a história produzem significação para o encontro do sujeito com o passado.

$\mathrm{Na}$ atualidade, com os avanços dos estudos nas duas áreas do conhecimento, ao se pensar que aquele que escreve textos literários está historicamente posicionado e influenciado pelo momento de sua escrita, compreende-se que a literatura pode sim ser considerada um fato histórico, tomada como diferentes representações da História, já que a literatura é essencialmente linguagem e, portanto, “o espaço por excelência onde a linguagem pode ser questionada, onde a estrutura pode ser contestada e os sentidos colocados em xeque" (LISBOA, 2008, p. 48). Dessa forma, "ao lado de retratar a realidade, a literatura cumpre a função primeira de vivificar a memória humana a respeito de sua história" (LISBÔA, 2008, p. 48).

Nesse sentido, o contexto em que tais obras são produzidas não pode ser ignorado, já que muito de seu significado se encontra em seu lugar de criação. A partir de tal afirmativa, parece, assim, que a historicidade da Literatura é relativa à sua própria essência. De certo modo, todo romance é histórico ao se considerar sua associação com um determinado contexto fático espaço-temporal. Porém, tal relação deve ser superada na medida em que a Literatura se compreende historicamente quando vai além de sua própria historicidade.

É a História Cultural ${ }^{4}$, em uma de suas vertentes mais recentes, que vai preocupar-se com as relações entre História e Literatura. Ao inovar o conceito que circunda a ideia de 
documento, ela possibilita uma revisão da História, transformando os materiais que a circulam em algo mais acessível ao sujeito. Tal fato acaba por exigir um trabalho mais atencioso com o texto desenvolvido pelo historiador.

Estas, segundo Pesavento, "se resolvem no plano epistemológico, mediante aproximações e distanciamentos, entendo-as como diferentes formas de dizer o mundo, que guardam distintas aproximações com o real" (2006, p. 3). A autora ainda acrescenta que História e Literatura correspondem a narrativas explicativas da realidade que, no tempo e no espaço, ganham novos ares, e com forte traço de permanência ancestral. Há muito tempo, pelo uso de suas diferentes formas, ambas, pela expressão da linguagem, sugerem o visto e o não visto do mundo (2006, p. 4). Acompanhando o ofício da História, o papel de engajamento da Literatura vai ganhando força. A crítica e a denúncia das injustiças sociais fazem parte das linhas de ambas, ficando evidente o fato de que não há Literatura sem o contato com a cultura e a sociedade trazidas por ela. É assim, que ela surgirá como uma forma de avaliação das estruturas vigentes bem como das inquietações existentes.

Hoje, são diversos os pontos que colocam Literatura e História em um mesmo debate, aproximando-as e entrecruzando suas narrativas; diferentes formas de entendimento de que seus discursos dão respostas às questões do sujeito sobre o mundo, respondendo a seus desejos e expectativas sobre a realidade. As duas áreas tratam o mundo tendo o texto como ponto de partida.

Quanto ao olhar teórico, são muitos os que trabalham com as aproximações e diferenças entre os dois temas. O estudioso Sevcenko, por exemplo, reitera o papel do historiador é o de se ocupar com a realidade, enquanto o escritor é atraído pelo "vir-a-ser", pelas múltiplas possibilidades de construção de algo (2003, p. 59).

Entretanto, Roger Chartier assume uma posição contrária a do primeiro teórico apresentado. Para ele, são muitas as razões que de alguma maneira contribuem para o não esclarecimento da distinção entre História e Literatura. A primeira seria "a evidenciação da força das representações do passado propostas pela literatura" (2009, p. 25), acompanhada do "fato de que a Literatura se apodera não só do passado, mas dos documentos e técnicas encarregados de manifestar a condição de conhecimento da disciplina histórica" (2009, p. 27), e da noção de que "no mundo contemporâneo, a necessidade de afirmação ou de justificação de identidades construídas [...] costuma inspirar uma reescrita do passado que deforma [...] as contribuições do saber histórico controlado. A capacidade crítica da história [...] deve submeter as construções interpretativas a critérios objetivos de validação ou de negação" (2009, p. 30). Para ele, essa é uma diferença que acaba por ser ofuscada pela "evidenciação da 
força das representações do passado propostas pela literatura", resultado da mencionada apropriação de fatos dos passados, que desloca para o campo da ficção literária o registro de acontecimentos e personagens históricos. Essa apropriação, afirma o teórico, cria o "efeito de realidade", conceito cunhado por Barthes, que trabalha com a multiplicação de notações concretas destinadas a carregar a ficção de um peso de realidade (CHARTIER, 2009, p. 24-5, 27-8).

Borges, ao mencionar os estudos de Chartier aponta também que para o estudioso francês:

todo documento, seja ele literário ou de qualquer outro tipo, é representação do real que se apreende e não se pode desligar de sua realidade de texto construído pautado em regras próprias de produção inerentes a cada gênero de escrita, de testemunho que cria "um real" na própria "historicidade de sua produção e na intencionalidade da sua escrita". Desta forma, todo tipo de texto possui uma linguagem específica, na qual foi produzido, própria de um segmento particular de produção, e esta ocorre considerando dadas regras peculiares ao meio intelectual de onde emerge, ao veículo em que será veiculada e ao público a que se destina (BORGES, 2010, p. 96).

O excerto acima evidencia o caráter complexo e plural das representações sociais e culturais dos diferentes grupos sociais. Nesse sentido, é refletir acerca das relações entre os "discursos proferidos com a posição social de quem os produz e de quem os utiliza" (BORGES, 2010, p. 96), tendo em vista a não neutralidade daquele que narra. Todo discurso produz e revela estratégias e práticas que tendem a impor uma autoridade (CHARTIER, 1990, p. 16-17).

Tais apontamentos levam ao entendimento do caráter não estático da narrativa; a literatura não está apenas no texto em si - o público também possui grande responsabilidade no processo de significação. Chartier (1994) reitera esta questão afirmando que

\begin{abstract}
as obras - mesmo as maiores, ou sobretudo, as maiores - não têm sentido estático, universal, fixo. Elas estão investidas de significações plurais e móveis, que se constroem no encontro de uma proposição com uma recepção. Os sentidos atribuídos às suas formas e aos seus motivos dependem das competências ou das expectativas dos diferentes públicos que delas se apropriam. Certamente, os criadores, os poderes ou os experts sempre querem fixar um sentido e enunciar a interpretação correta que deve impor limites à leitura (ou ao olhar). Todavia, a recepção também inventa, desloca e distorce (CHARTIER, 1994, p. 09).
\end{abstract}

A Literatura deve ser compreendida como tendo como referências os diversos contextos que a cercam (cultura, social, filosófico). Ela é dinâmica, é um processo envolvendo atores historicamente situados em contextos sociais claramente definidos. 
Ao tomar a Literatura como fonte historiográfica, de acordo com Pesavento, é que o estudioso toma conhecimento de resquícios de um passado que se transformará em uma fonte carregada de nova significação e que, de alguma, forma, (re)orientarão seu olhar de historiador. A autora ainda completa sua arguição afirmando que "se são discursos, são representações discursivas sobre o que se passou; se são imagens, são também construções sobre o real" (2004, p. 04).

Ademais, Pesavento pontua,

\begin{abstract}
a literatura permite o acesso à sintonia fina ou ao clima de uma época, ao modo pelo qual as pessoas pensavam o mundo, a si próprias, quais os valores que guiavam seus passos, quais os preconceitos, medos e sonhos. Ela dá a ver sensibilidades, perfis, valores. Ela é fonte privilegiada para a leitura do imaginário. [...] Para além das disposições legais ou códigos de etiquetas de uma sociedade, é a literatura que fornece os indícios para pensar como e por que as pessoas agiam desta e daquela forma (PESAVENTO, 2003: 82-83).
\end{abstract}

Além da relação exposta acima, se faz necessária a defesa da necessidade intrínseca ao sujeito que é o do ato de narrar. De acordo com Miller (1990), desde tempos imemoriais somos perpassados por narrativas e necessitamos delas para nos constituirmos enquanto seres humanos. Durante períodos de mínima organização tribal, desenvolvemos narrativas minimalistas para passar informações, conhecimentos, valores e assim nos organizarmos socialmente (HOWITT-DRING, 2011).

Para Theodor Adorno (2003), a humanidade enfrenta grandes desafios no que diz respeito à narração, desde o pós-guerra. Para ele, o contexto da guerra mudou a forma como se produzia e se compartilhava conhecimentos. Isso afetou significativamente a literatura, já que, "se o romance quiser permanecer fiel à sua herança realista e dizer como realmente as coisas são, então ele precisa renunciar a um realismo que, na medida em que reproduz a fachada, apenas a auxilia na produção do engodo. (ADORNO, 2003, p. 57). Nesse sentido, percebe-se que a memória surge como uma aliada ao processo de narração histórica, visto que nunca antes observou-se um número tão grandes de publicações de diários, de livros de cartas e, ainda, livros que unem memórias à ficção. A memória, apesar de perpassada e constituída pelo subjetivismo e pela perspectiva pessoal, parece dar conta de acontecimentos históricos que o narrador moderno não mais conseguia narrar através do simples relato.

Assim, na contemporaneidade, encontramos uma sociedade que ficcionaliza suas vivências e memórias e, frequentemente, as compartilha de maneira multimídia e espera que elas sejam lidas com o mesmo afinco com que se necessita ler narrativas de outros. A narração, dessa maneira, segundo Miller (1990), é intrínseca ao ser humano. Ao 
transformarmos um fato em linguagem o ressignificamos, escolhendo as partes que serão postas em evidência, em segundo plano ou excluídas, tornando-o ficção.

Nesse sentido, Beatriz Sarlo, no livro Tempo passado: cultura da memória e guinada subjetiva (2007), desmistifica o lugar da história, trazendo a subjetividade como parte integrante do relato, mesmo que este seja feito por alguém que o tenha presenciado. Afirma a autora que, assim, “apresenta-se como novidade algo que pertenceu à ordem do evidente: se o passado não foi vivido, seu relato só pode vir do conhecido através de mediações e, mesmo se foi vivido as mediações fazem parte desse relato (SARLO, 2007, p.92).

Dessa forma, compreende-se que o relato é interpelado pelo sujeito. Essa ideia não apenas questiona a noção de história como verdade, mas também impõe o problema de fontes. Como dar voz a uma vasta gama de diferentes indivíduos? A sociedade está em busca de uma verdade ou de várias e plurais verdades? Assim, através destes questionamentos impõe se um novo mosaico, que impugna ao indivíduo um diferente olhar em relação às narrativas do passado.

É baseado nas das indagações de um contexto trazido pela Literatura, em sua pesquisa, que a relação desta com a História torna-se frutífera e enriquecedora. Questões levantadas pelos estudiosos trazem à tona a descoberta, nas linhas literárias, de novas pistas para investigação do passado.

\section{Considerações finais}

Em suma, a Literatura só existe a partir de seu contato com o social e cultural, o escritor está completamente inserido em um contexto quanto escreve. Dessa maneira, diante da discussão apresentada, entende-se que as obras ficcionais podem ser lidas como entretenimento ou com lócus privilegiado para a leitura da sociedade em foco, além de contribuir para os avançosna dimensão cultural como para questionarmos e refletirmos acerca das questões sociais, tornando-se uma fonte documental privilegiada para pensar a História. Contudo, tal entendimento, da Literatura como espaço de estudo historiográfico, traz consigo a importância do cuidado que o historiador deve ter ao lidar com as diferentes categorias utilizadas por ela para narrar. Lidar com as manifestações literárias que sempre apresentam traços heterogêneos, caracteres múltiplos e contraditórios, exige um exame minucioso de cada autor e dos pormenores que particularizam cada obra. 


\section{Referências}

ADORNO, Theodor. Posição do narrador no romance contemporâneo. In ADORNO, T. Notas de Literatura I. Rio de Janeiro: Editora 34, 2003, 54-63

BORGES, Valdeci Rezende. História e Literatura: Algumas Considerações. In: Revista de Teoria da História, Ano 1, n. 3, Goiás: junho/ 2010.

CHARTIER, Roger. A história cultural: entre práticas e representações. Lisboa: Difel, 1990.

, Roger. A ordem dos livros: Leitores, autores e bibliotecas na Europaentre os séculos XIV e XVIII. Trad. Mary Del Priore. -2.ed.- Brasília: Editora da UnB, 1994.

, Roger. A história ou a leitura do tempo. Belo Horizonte: Autêntica, 2009.

COMPAGNON, Antonie. O demônio da teoria: literatura e senso comum. Belo Horizonte: Ed. UFMG, 1999

HOWITT-DRING, Holly. Making micro meanings: reading and writing. Short Fiction in Theory. Ed. Alissa Cox. Bristol: Intellect Ltd Articles, 2011.47-58

HUTCHEON, Linda. Poética do pós-modernismo: história, teoria e ficção. Rio de Janeiro: Imago, 1991.

LISBOA, Noeli. A oposição silêncio e interdito no funcionamento da linguagem e suas relações com a ideologia. Porto Alegre: UFRGS, 2010. Vol. 24, 151-164

LUKÁCS, George. La novela histórica. Tradução: Jasmim Reuter. -1.ed. México D.F.: Era, 1966.

MILLER, J.Hillis. Narrative. Critical Terms for Literary Study. Ed. Frank Lentricchia and Thomas McLaughlin.Chicago: TheUniversity of Chicago Press, 1990. 66-79.

PESAVENTO, Sandra Jatahy. O Mundo Como Texto: leituras da História e da Literatura. História da Educação, Pelotas, p. 31 - 45, 01 set. 2003.

ed. , Sandra Jatahy. História \& História Cultural. Belo Horizonte: Autêntica, 2004, 2 , Sandra Jatahy. História \& literatura: uma velha-nova história. Nuevo Mundo, Mundos Nuevos, Debates, 2006.2 Disponível em: http://nuevomundo.revues.org/index1560.html.

SARLO, Beatriz. Tempo passado: cultura da memória e guinada subjetiva. Tradução de Rosa Freire d'Aguiar. São Paulo: Companhia das Letras; Belo Horizonte: UFMG, 2007.

SEVCENKO, Nicolau. Literatura como missão: tensões sociais e criação cultural na Primeira República. São Paulo: Brasiliense, 2003, 2 ed. 
WHITE, Hayden. Trópicos do discurso: ensaios sobre a crítica da cultura. Trad. Alípio Correia de Franca Neto. $2^{\text {a }}$ ed. São Paulo: EDUSP, 2001. 